\title{
Mapping the Future of KM through Earl's KM Taxonomy Lens
}

John Girard, Middle Georgia State University, john@johngirard.net

Vincent Ribière, IKI-SEA - Bangkok University, vribiere@gmail.com

\begin{abstract}
This paper chronicles exploratory research about the use of content analysis to guide the future knowledge management research agenda. The responses of 35 international knowledge management experts answering a question about the future of knowledge management were considered. The interviews, which were created as part of a different project, are freely available online. This secondary data was analyzed using a series of content analysis techniques to determine which elements of Michael Earl's knowledge management taxonomy were most prevalent. A dictionary of terms reflecting Earl's taxonomy was created. The top three schools that emerged were the engineering, cartographic and systems schools, all of which belong to the high-order category technocratic. A series of qualitative comments are included to expand on the quantitation results and with a view to stimulating future research.
\end{abstract}

Keywords: knowledge management, future, taxonomy, Michael Earl, dictionary

\section{Introduction}

The future of knowledge management has been an area of great interest to academics and practitioners since its very inception. The pioneering authors of some of the very first works in the field looked to the future with great hope and anticipation. In The Wealth of Knowledge, Tom Stewart concluded his manuscript by writing:

It's time we learned anew. Organizations are complex human systems. They can adapt, grow, and improve the way human beings do - without having to be taken apart, the parts spread out over the garage floor by a consulting mechanic. Organizations are not so much collections of parts as they are connections of brain cells, nerves, and sinews. To discover this is to discover the power of knowledge set free and of technology made human. It is to discover that it's possible to improve not only a company's performance today, but it responsiveness, its repertoire of skills, and its capacity to deal with the future (2001, p336).

In The Knowledge Creating Company, Nonaka and Takeuchi wrote:

We believe the future belongs to companies that can take the best of East and the West and start building a universal model to create new knowledge with their organizations. Nationalities will be of no relevance, as we will no longer identify the key characteristics of successful companies as being Japanese, American or European. Success in the new "knowledge society" will be judged on the basis of knowledge-creating capabilities. To become knowledge-creating companies, 
managers in the East and the West need to build and manage multiple conversions, spirals, and syntheses, and not be content simply to carry out a unidimensional boxing match ... The speed by which conversions, spirals, and syntheses take place, therefore, will be a key capability in the future (Nonaka \& Takeuchi, 1995, pp. 245-6).

In If Only We Knew What We Know, O'Dell and Grayson eloquently reminded us, "There is no conclusion to managing knowledge and transferring best practices, it is a race without a finishing line. And this is even more true in the knowledge era as we move toward the Millennium (O'Dell and Grayson, 1998, p. 221).”

The wise words of these pioneering experts charted the course for many researchers over the past three decades. According to Google Scholar, the Nonaka and Takeuchi's book alone, The Knowledge Creating Company, has been cited at least 32,739 times.

Perhaps the time is right to chart the next decade of knowledge management research. What topics are worthy of our collective research power? To answer these questions and others, the researchers decided to analyze the comments of a wide variety of professionals involved in the field of knowledge management through the lens of Michael Earl's KM Taxonomy (2001). Specifically, the experts' views of the future of knowledge management were analyzed with a view to determining if there was general agreement on what the future might hold. This inductive approach, we believed, might lead to interesting research opportunities for the future.

\section{Research Method}

We used an interpretivist qualitative paradigm for this research (Patton 2002, Merriam 2002). Two quantitative content analyses were conducted supported by a qualitative content analysis. The first content was used to develop a dictionary based on Earl's Knowledge Management taxonomy and framework. The second one was used to interpret/map the opinions of the KM experts through the lens of the Earl's taxonomy and framework. A final qualitative content analysis was used to support the findings of the combinations of the 2 quantitative content analyses.

\section{Expert Selection}

A purposive sample (Merriam, 2002) seemed to be the most appropriate sample choice to answer our research question. We accessed previously recorded videos from 35 active Academics, Researchers and Practitioners in the world of Knowledge Management. Many have been teaching, writing and practicing KM for more than 20 years. 6\% (2) are strictly KM academics; $17 \%$ (6) are KM practitioners; and the majority $77 \%$ (27) act as both academics and practitioners. Most of them will have immediate name recognition for International $\mathrm{KM}$ organizations. They represent 12 countries from all the 5 continents. 


\section{Knowledge Management Taxonomies}

The most difficult phase the project was to determine how to classify the experts' views of the future of knowledge management. After reviewing a variety of projects that considered knowledge management taxonomies (Earl, 2001; Nie, Ma, \& Nakamori, 2007; Von Nordenflycht, 2010; Lambe, 2014; Hicks, Dattero, \& Galup, 2006), Michael Earl's five-year research project, in which he proposes a taxonomy of the strategies, or schools, for knowledge management, was selected. This seminal work remains the most cited paper in the domain of knowledge management taxonomies. Although the research is now 15 years old, it has passed the test of time and offers a robust model for considering the future. Earl's work continues to command the respect of researchers. We acknowledge that this decision was somewhat arbitrary, and we encourage other researchers to apply different methods to the problem. Nevertheless, we believe this exploratory research adds value.

Earl's acknowledged purpose was to help guide executives on choices to initiate knowledge management projects according to the goals, organizational charter, and technological, behavioral, or economic biases (Earl, 2001). The basis of Earl's work aligns very well with the views of our experts as they described the future of knowledge management. In categorizing the schools, Earl uses the three biases (technological, behavioral, and economic) as the high order categories. He further divided the categories into seven unique schools, a summary of each is in Table 1.

Table 1. Earl's schools of Knowledge Management (Adapted from Earl, 2001)

\begin{tabular}{|l|l|l|l|l|}
\cline { 2 - 5 } \multicolumn{1}{c|}{} & \multicolumn{3}{c|}{ Technocratic } & \multicolumn{1}{c|}{ Economic } \\
\hline School & System & Cartographic & Engineering & Commercial \\
\hline Aim & Technology & Maps & Processes & Income \\
\hline Philosophy & Knowledge & $\begin{array}{l}\text { Knowledge } \\
\text { directories }\end{array}$ & $\begin{array}{l}\text { Knowledge } \\
\text { flows }\end{array}$ & $\begin{array}{l}\text { Knowledge } \\
\text { assets }\end{array}$ \\
\hline
\end{tabular}

\begin{tabular}{|l|l|l|l|}
\cline { 2 - 4 } \multicolumn{1}{c|}{} & \multicolumn{3}{c|}{ Behavioral } \\
\cline { 2 - 4 } Attribute & Organizational & \multicolumn{1}{c|}{ Spatial } & Strategic \\
\hline Focus & Networks & Space & Mindset \\
\hline Aim & $\begin{array}{l}\text { Knowledge } \\
\text { pooling }\end{array}$ & $\begin{array}{l}\text { Knowledge } \\
\text { exchange }\end{array}$ & $\begin{array}{l}\text { Knowledge } \\
\text { capabilities }\end{array}$ \\
\hline Philosophy & Collaboration & Contactivity & Consciousness \\
\hline
\end{tabular}


Technocratic. Earl (2001) classifies his first group technocratic as each of the schools relies on information technology to assist knowledge workers. For example, information technology provides knowledge bases, knowledge directories, or knowledge flows. Earl (2001) suggests that three knowledge management schools should be part of this taxonomy: systems, cartographic, and engineering.

The purpose of the system school is "to capture specialist knowledge in knowledge bases which other specialist or qualified people can access" (Earl, 2001, p. 218). For many, this is the essence of knowledge management the ability to access knowledge quickly to help solve an organizational challenge.

The second category - the cartographic school - is not surprising based on mapping organizational knowledge. The purpose of this school is "to make sure knowledgeable people in the organization are accessible to others for advice, consultation, or knowledge exchange" (Earl, 2001, p. 220). Finding the person who holds the particular knowledge is the key to this school. Unlike the previous school, which concentrates on tacit knowledge, this school is applicable to both tacit and explicit knowledge exchanges. Perhaps the best analogy for this school is the yellow pages as its main aim is the establishment of a knowledge directory that allows people to connect.

The last in technocratic taxonomy is the engineering school, which focuses on two related concepts. The first is that "performance of business processes can be enhanced by providing operating personnel with knowledge relevant to their task" and second that "management processes are inherently more knowledge-intensive than business processes" (Earl, 2001, p. 221). Earl argues that in addition to decision-related information, best practice knowledge is also very important.

Economic. A single school exists within the Economic category that is entitled the Commercial school. Earl (2001) defines this school economic because "it is overtly and explicitly concerned with both protecting and exploiting a firm's knowledge or intellectual assets to produce revenue streams" (p. 222).

Behavioral. The last group of Earl's (2001) schools is the behavioral group, which stems from the social sciences and focuses on the creation, sharing, and use of knowledge as a resource. Concentrating on collaboration, contactivity, and consciousness, many consider this group to be the people group, once again emphasizing the notion that technology is not the exclusive foundation of knowledge management.

Earl (2001) describes the organizational school as "the use of organizational structures, or networks to share or pool knowledge" (p. 223). Clearly, the key to success of this school is maximizing the amount of knowledge sharing and thereby reducing the time wasted seeking knowledge.

The spatial school provides "a design for emergence philosophy of knowledge management .. . it centers on the use of space or spatial designs to facilitate knowledge exchange" (Earl, 2001, p. 225). Many scholars refer to this school using a water cooler metaphor - as workers gather at the water cooler to exchange information and knowledge. In Working Knowledge, Davenport \& Prusak (1998) argue convincingly that conversations around the water cooler provide an opportunity for knowledge transfer (presumably tacit knowledge). They warned us of modern 
management practices that consider socializing wasteful or purport virtual offices as the way of the future.

The strategic school "sees knowledge management as a dimension of competitive strategy" (Earl, 2001, p. 227). This school seeks to exploit knowledge itself as a resource. Those practicing the strategic school consider knowledge, on its own, to be a strategic advantage. Earl cites examples of companies, which harvest knowledge as a resource.

\section{Developing Earl's Taxonomy Dictionary}

This project opted to use content analysis techniques to map the expert's views on the future of knowledge management to Earl's taxonomy or schools of knowledge management. Content analysis is an effective qualitative method to make sense of media collected as part of interviews (Holstein \& Gubrium, 2012; Krippendorff, 2004; Krippendorff \& Bock, 2009; Neuendorf, 2002 Weber, 1990).

To achieve this goal, a content analysis dictionary (Table 2) was developed based on the key terminology used by Earl to describe each of the schools. For example, the cartographic school, which Earl describes as "to make sure knowledgeable people in the organization are accessible to others for advice, consultation, or knowledge exchange" (Earl, 2001, p. 220), we selected the following words for the dictionary: access, advice, connect, consult, culture, directory, enterprise, exchange, incentive, map, network, people, profile, and share. To ensure that all forms of the words were discovered, the root of the word has added with wildcards. For example, acces* was input to ensure that words such as access, accessing, accessed, etc. would all be capture.

Once the dictionary was developed a trial was conducted using a variety of knowledge management related sources to determine if the major concepts were captured by the dictionary. After a series of modifications, the Earl taxonomy dictionary was finalized with a total of 80 entries. As with all content analysis dictionaries, there will almost certainly be omissions in the current dictionary, and we expect other researchers to review, scrutinize and further refine the dictionary. The current dictionary is deemed suitable for this exploratory research.

\section{Mapping Experts visions with Earl's Taxonomy Dictionary}

The videos analyzed are a series of recordings named, IKI-Talks (http://ikitalks.iki-sea.org) recorded by the Institute for Knowledge and Innovation Southeast Asia (IKI-SEA), Bangkok University, Bangkok, Thailand. The participants constitute an International Visiting Faculty for IKI-SEA's Research PhD Program in Knowledge and Innovation Management. The recordings were created during the period 2012-2014 as original responses to a six (6) Question Interview Series.

The collection includes interviews with 35 experts answering a wide a variety of questions related to knowledge management and innovation. Of particular interest to this project were the experts' responses to a question about the future, which represent 54 minutes of dialogue. 
Table 2: Earl's Taxonomy Dictionary

\begin{tabular}{|c|c|c|}
\hline Behavioral & Economic & Technocratic \\
\hline $\begin{array}{cl}\text { - Organizational } \\
\text { - Collaborat* } \\
\text { - Communicat* } \\
\text { - Communit* } \\
\text { - } \text { Culture* } \\
\text { - Network* } \\
\text { - Pool* } \\
\text { - Social } \\
\text { - shar* } \\
\text { Spatial } \\
\text { - Acces* } \\
\text { - Contact* } \\
\text { - Encourag* } \\
\text { - Exchang* } \\
\text { - Place* } \\
\text { Strategic } \\
\text { - Artifact* } \\
\text { - Business } \\
\text { - Capabil* } \\
\text { - Consciousness } \\
\text { - Mindset } \\
\text { - Rhetoric } \\
\text { Strateg* }\end{array}$ & $\begin{array}{l}\text { - Commercial } \\
\text { - Asset* } \\
\text { - Commercializ* } \\
\text { - Income } \\
\text { - Intellectual } \\
\text { - Know-how } \\
\text { - Process* } \\
\text { - Registered } \\
\text { - Team* } \\
\text { - revect } \\
\text { revenue* }\end{array}$ & 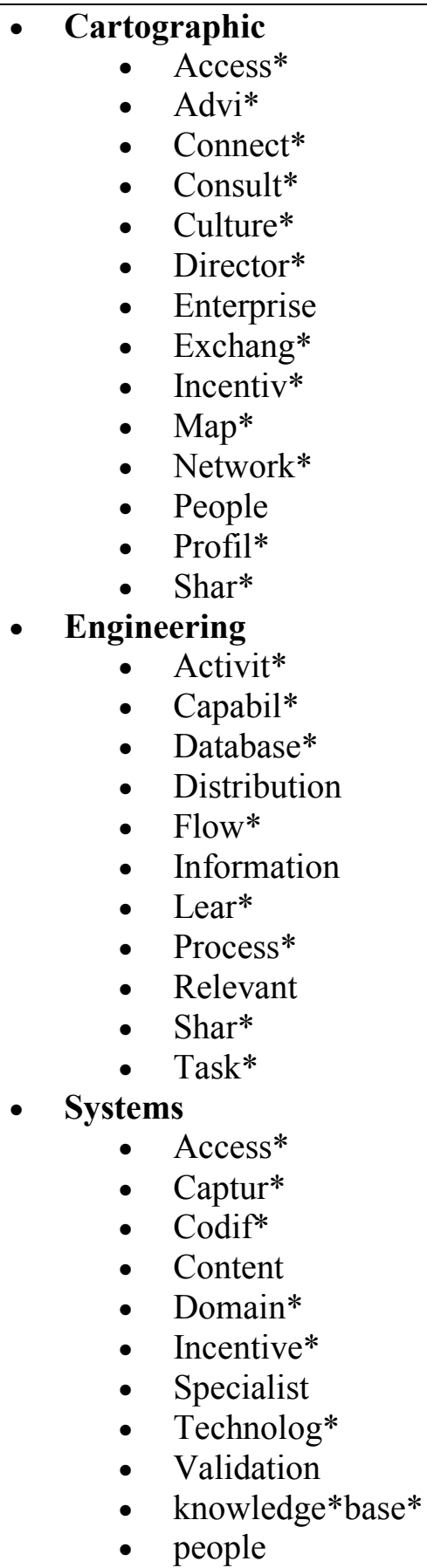 \\
\hline
\end{tabular}


The interviews were recorded in two separate batches and used a slightly different questions. The question posed for the first group of interviews was What would be the most important knowledge management topic in the future? For the second set of interviews, the question asked was inadvertently changed to How do you foresee knowledge management as a discipline in the future? Although this is not ideal, we were satisfied that the future theme was maintained throughout both sets of interviews. However, we did opt to complete a t-test to see if the frequently of responses varied from one group to another based on the 80 entries in the dictionary. There was not a significant difference in the frequency of words between the first question $(\mathrm{M}=7.1, \mathrm{SD}=19.76)$ and the second question $(\mathrm{M}=6.8, \mathrm{SD}=18.96) ; \mathrm{t}(158)=0.09, \mathrm{p}=$ 0.922. Based on this finding we decided to continue with both questions.

The content of all 35 interviews was transcribed by a reliable commercial transcription service. The transcription facilitated the use of content analysis program (Yoshikoder) to classify/map the expert's descriptions into Earl's schools. The analysis was first completed at the bias-level or high order categories (technological, behavioral, and economic) (Figure 1) and the results were as shown below:

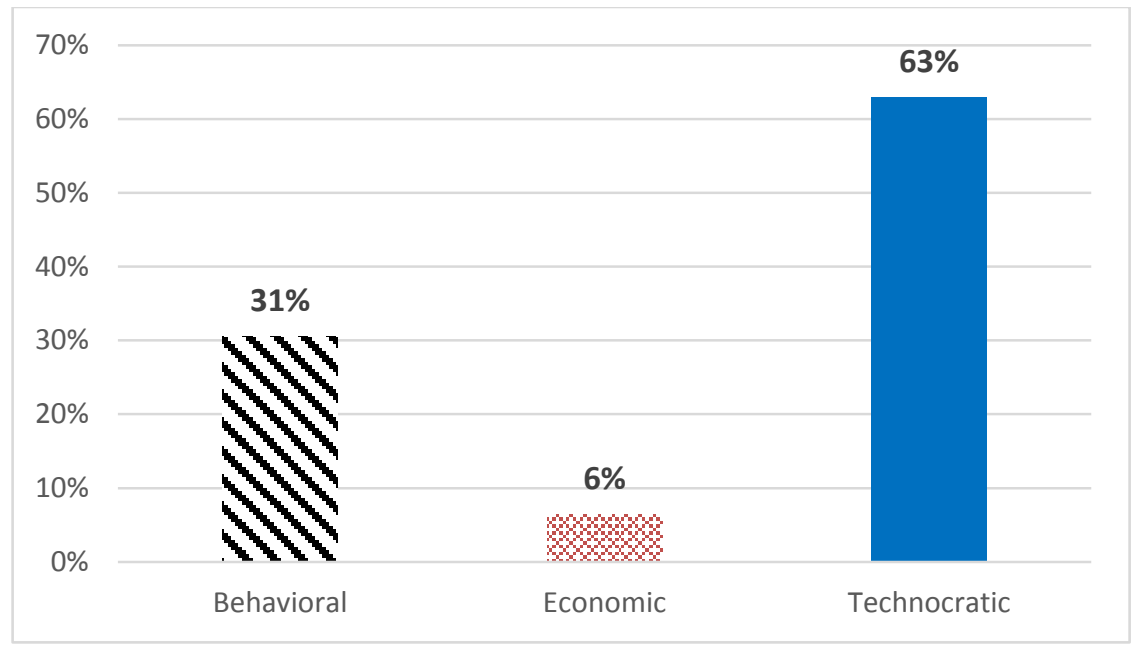

Figure 1. Distribution of High Order Categories

The Technocratic High Order Category significantly stood out compared to the 2 other categories (Behavioral (31\%) and Economic (6\%)) by representing 63\% of the keywords used by experts in their answers. A more detailed analysis, by the school level (organizational, spatial, strategic, commercial, cartographic, engineering, and systems) (Figure 2) was conducted to better understand which component of each High Order Category was prominent, and the results were as shown below: 


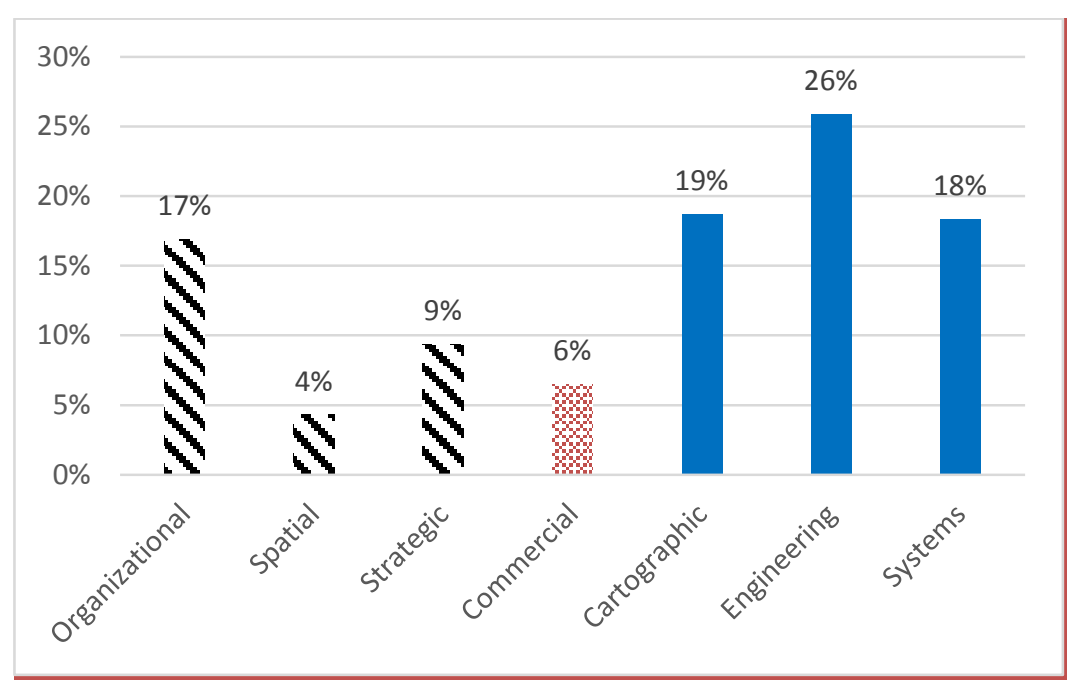

Figure 2. Distribution of Schools

For the Technocratic High Order of Category, the focus on content related to the Engineering School was significantly higher (26\%) than on the 2 other schools (Cartographic (19\%) and Systems (18\%). For the Behavioral High Order of Category, the focus on content related to the Organizational school was significantly higher (17\%) than on the 2 other schools (Strategic (9\%) and Spatial (4\%). Since the Economic Higher of Category is only composed of the Commercial school, no comparison was necessary. The only demographic data available for analysis was gender. A t-test confirmed that there was no significant difference between men and women's answers.

\section{Qualitative Content Analysis}

Much as Michael Earl designed his study to help guide executives on choices to initiate knowledge management projects; this study sought to provide a glimpse of the future to help steer research. The results of the experts interviewed suggest that technocratic and behavior biases will continue to dominate the domain. Within these high-order categories, it is less clear which of the schools, if any, merit the most attention. These conclusions are based solely on the summarized results of the quantitative content analysis in which the aim was to categorize the expert's views. In the original study, Earl suggested, "the schools are not mutually exclusive. Indeed, two or three of them sometimes have been observed in the same organization" (Earl, 2001, p. 216).

As powerful as content analysis is a social science methodology there remains a longstanding limitation. Kracauer (1952) warned that "overemphasis on quantification tends to lessen the accuracy of analysis" and that "one-sided reliance on quantitative content analysis may lead to a neglect of qualitative exploration, thus reducing the accuracy of analysis" (p. 631). This seems to build on Given Earl's recognition that the schools are not mutually exclusive. To ensure this project did not overemphasize the quantitative content analysis, and the perception of exclusivity, we opted to include a qualitative review. 
Table 3 includes a series of extracts from the experts that may help guide researchers in their future work. These extracts are not meant to be all encompassing but rather are designed to offer some ideas that might stimulate research.

Table 3. Illustrative comments from Experts

\begin{tabular}{|c|c|}
\hline Extract & Categories \\
\hline $\begin{array}{l}\text { "I believe knowledge utilization is going to be of the maximum essence. The reason why, } \\
\text { because it involves a lot of processes in the organization wherein the knowledge is being } \\
\text { utilized. And unless and until the knowledge is utilized, it cannot be of any value to the } \\
\text { organization's goals." Manasi Shukla, IKI-Talks Video }\end{array}$ & $\begin{array}{l}\text { Economic } \\
\text { Technocratic }\end{array}$ \\
\hline $\begin{array}{l}\text { "For me the most important capabilities that we need to increase across organizations and } \\
\text { also in society, are the ability to make sense of information, so this is something I would } \\
\text { call information or knowledge literacy." Waltraut Ritter, IKI-Talks Video }\end{array}$ & $\begin{array}{l}\text { Behavioral } \\
\text { Technocratic }\end{array}$ \\
\hline $\begin{array}{l}\text { "What I'd like to say it is about making expertise visible and making it more accessible. } \\
\text { Expertise is a very rare resource, the world needs the benefits of expertise, it tends to be } \\
\text { locked up in individual heads, therefore not leveraged and we don't benefit from it." } \\
\text { Kate Andrews, IKI-Talks Video }\end{array}$ & $\begin{array}{l}\text { Behavioral } \\
\text { Technocratic }\end{array}$ \\
\hline $\begin{array}{l}\text { "I believe there's a lot going on into a thing we call collective knowledge especially } \\
\text { because we are now empowered by social network and social media." Rivadávia C. } \\
\text { Drummond de Alvarenga Neto, IKI-Talks Video }\end{array}$ & $\begin{array}{l}\text { Behavioral } \\
\text { Technocratic }\end{array}$ \\
\hline $\begin{array}{l}\text { "Knowledge management is still largely a technological activity. And we've developed } \\
\text { amazing systems that can help us capture, and share, and re-use knowledge and } \\
\text { information. But when we think of these things as technologies, we tend to miss the point } \\
\text { about how and why knowledge workers are really using them." Steve Barth }\end{array}$ & $\begin{array}{l}\text { Behavioral } \\
\text { Technocratic }\end{array}$ \\
\hline $\begin{array}{l}\text { "I feel that would be more like how to use for example the social technology, in order to } \\
\text { foster for example, the knowledge exchange or knowledge sharing." Aurilla Aurelie } \\
\text { Arntzen, IKI-Talks Video }\end{array}$ & $\begin{array}{l}\text { Behavioral } \\
\text { Technocratic }\end{array}$ \\
\hline $\begin{array}{l}\text { "I think how we more effectively communicate on a face to face basis and how the } \\
\text { technology sort of morphs and brings that, brings us the ability to engage much more } \\
\text { productively when we are virtual or remote." Arthur Shelly, IKI-Talks Video }\end{array}$ & $\begin{array}{l}\text { Behavioral } \\
\text { Technocratic }\end{array}$ \\
\hline $\begin{array}{l}\text { "If the paradigm of KM changes from technological viewpoint to managerial, and social } \\
\text { and technical viewpoint, then systematic education of KM must bring a new state of mind } \\
\text { in using knowledge sharing culture collaborative and innovative work." Michel } \\
\text { Grunstein, IKI-Talks Video }\end{array}$ & $\begin{array}{l}\text { Behavioral } \\
\text { Technocratic }\end{array}$ \\
\hline $\begin{array}{l}\text { "I think transformation of knowledge worker to knowledge cultivator. Because } \\
\text { knowledge cultivator as wine producer he chose the soil, plants and he care knowledge, } \\
\text { and if he got fruits to share between participants which is most important in knowledge } \\
\text { management." Eunika Laurent Mercier, IKI-Talks Video }\end{array}$ & $\begin{array}{l}\text { Behavioral } \\
\text { Technocratic }\end{array}$ \\
\hline $\begin{array}{l}\text { "I think one of the most pressing topics for KM is an internal one, is how we become } \\
\text { more integrated and coherent as a discipline." Patrick Lambe, IKI-Talks Video }\end{array}$ & None \\
\hline $\begin{array}{l}\text { "I still think that there is still a lot of work that needs to be done in trying to understand or } \\
\text { to find ways to better transfer knowledge or to better elicit or articulate knowledge." } \\
\text { Vincent Ribiere, IKI-Talks Video }\end{array}$ & None \\
\hline $\begin{array}{l}\text { "What has always been in the past, to have your old mentor assist human intelligence and } \\
\text { decision making." Dave Snowden, IKI-Talks Video }\end{array}$ & None \\
\hline
\end{tabular}


Worthy of note is the discovery that most comments could apply to more than one of the highorder categories, almost certainly supporting Earl's thesis on nonexclusively. Equally intriguing are the thoughtful comments by some experts that do not contain dictionary entries associated with a particular school and therefore are not included in the quantitative results.

Out of the main themes that emerged from the qualitative content analysis of the 35 experts responses is the existence or not of $\mathrm{KM}$ in the future. Every expert seems to agree that organizations rely more and more on knowledge to operate and to compete (Knowledge-based economy) and consequently, its proper and systematic management is ineluctable. The debate remains on will it keep the same name of "Knowledge Management" and will it remain the responsibility of a "KM unit", or will it just become mainstream and become part of every activity at different levels of the organization and across all disciplines? It is interesting to relate this finding to another interview question that was asked of the same group of experts about what they perceive remains the main success barriers of KM (Ribiere, Calabrese 2016). Seven main categories of reasons emerged from this study: culture, measurement/benefits, strategy, organizational structure, governance and leadership, IT-related Issues, and lack of KM understanding/standards.

Another theme that emerged from our content analysis is the concept of collective knowledge. While up to now, KM mainly focused on managing knowledge internally in the organization, the future of $\mathrm{KM}$ will have to deal with collective, fragmented and spread knowledge. The fast development of the social network is an illustration of it, as well as dealing with Big Data. Supporting collaborative endeavors and collaborative decision making is a remaining KM challenge.

Another theme that emerged was directly related to the organizational emphasis of KM. Experts forecast KM to become a much more strategic issue in the future that it is currently.

The results of the quantitative content analysis show a strong emphasis on technocratic approaches, since the support of technology will be necessary to reach most of these previous objectives where quantity and distance will remain a challenge.

Even though the results of the quantitative content analysis placed "Behavioral" in second position, the human/social role of KM was emphasized by most of the experts. Knowledge will always remain in the head of people and if they are not able/willing to share it and to benefit from its sharing, KM activities will lose their value. More efforts/research need to be continued in this aspect to turn KM into an invisible powerful supporting tool.

In this case, we believe the qualitative content analysis corroborates or confirms our quantitative content analysis findings. Specifically, our discovery that many experts used keywords associated with more than one category aligns with our quantitative finding that a significant difference did not exist.

\section{Conclusions}

This aim of this exploratory research was to present areas that offer interesting knowledge management research opportunities for the future. One of the contributions of this paper is the 
creation of a dictionary of terms that reflects Michael Earl's KM taxonomy. This a novel approach that allowed us to look and to interpret experts' opinions through a particular lens. We believe that this dictionary could be re-used in various research to better analyze the dominating points of view of $\mathrm{KM}$ related documents or interviews. As a future research, the created dictionary will benefit from being further tested, validated and expanded to cover a larger span of $\mathrm{KM}$ related terms and concepts.

Another contribution of this research is to realize, from the 35 experts' opinions, that a technocratic approach to KM is likely to lead its future. Not in a way where technology will automate KM, but in a way where human and social interactions will be supported/empowered by KM technologies. Human will always remain at the center of KM activities.

\section{References}

Davenport, T. H. \& Prusak L. (1998). Working knowledge: How organizations manage what they know. Boston: Harvard Business School Press.

Earl, M. (2001). Knowledge management strategies: Toward a taxonomy. Journal of Management Information Systems, 18(1), 215-233.

Hicks, R. C., Dattero, R., \& Galup, S. D. (2006). The five-tier knowledge management hierarchy. Journal of Knowledge Management, 10(1), 19-31.

Holstein, J. A., \& Gubrium, J. F. (2012). Varieties of narrative analysis. Los Angeles: Sage.

Kracauer, S. (1952). The Challenge of Qualitative Content Analysis. The Public Opinion Quarterly, 16(4), 631-642.

Krippendorff, K. (2004). Content analysis: An introduction to its methodology. Thousand Oaks, Calif: Sage.

Krippendorff, K., \& Bock, M. A. (2009). The content analysis reader. Thousand Oaks, Calif: Sage Publications.

Lambe, P. (2014). Organising Knowledge: Taxonomies, Knowledge and Organisational Effectiveness: Elsevier Science.

Merriam, S. B. (2002). Qualitative research in practice. San Francisco: Jossey-Bass.

Neuendorf, K. A. (2002). The content analysis guidebook. Thousand Oaks, Calif: Sage Publications.

Nie, K., Ma, T., \& Nakamori, Y. (2007). Building a taxonomy for understanding knowledge management. Electronic Journal of Knowledge Management, 5(4), 453-466.

Nonaka, I., \& Takeuchi, H. (1995). The knowledge-creating company: how Japanese companies create the dynamics of innovation. New York: Oxford University Press.

O'Dell, C., \& Grayson, C. J. (1998). If only we knew what we know: the transfer of internal knowledge and best practice. New York: Free Press.

Patton, M. Q. (1990). Qualitative research \& evaluation methods. SAGE Publications, Inc. 
Ribiere, V. \& Calabrese, F. (2016). Why are companies still struggling to implement knowledge management? Answers from 34 experts in the field. In: Liebowitz, J. (ed.) Successes and Failures of Knowledge Management. Elsevier.

Stewart, T. A. (2001). The wealth of knowledge: intellectual capital and the twenty-first century organization. New York: Currency.

Venkatesh, V., Brown, S., \& Bala, H. (2013). Bridging the Qualitative-Quantitative Divide: Guidelines for Conducting Mixed Methods Research in Information Systems. MIS Quarterly, 37(1), 21-54.

Von Nordenflycht, A. (2010). What is a professional service firm? Toward a theory and taxonomy of knowledge-intensive firms. Academy of Management Review, 35(1), 155174.

Weber, R. P. (1990). Basic content analysis. Newbury Park, Calif: Sage Publications.

\section{Authors' Biographies}

John Girard holds the Peyton Anderson Endowed Chair in Information Technology at Middle Georgia State University's School of Information Technology. His current research interests include how technology, leadership and culture enable knowledge management, innovation, and globalization. John is founder and Chief Knowledge Strategist of Sagology (www.sagology.com), a firm dedicated to connecting people to facilitate collaboration, learning, and knowledge sharing through keynotes, workshops, and consulting. To learn more, visit www.johngirard.net.

Vincent Ribière is the Managing Director and co-founder of the Institute for Knowledge and Innovation Southeast Asia (IKI-SEA), a Center of Excellence of Bangkok University. He is an Associate Professor at Bangkok University. He is the co-founder and the Program Director of the $\mathrm{PhD}$ program in Knowledge and Innovation Management (KIM) and the Founder and CoProgram Director of the newly created Master in Business Innovation (MBI). As a KM and Innovation consultant he has worked with a number of international organizations. He is also the founder and Animator of the iklub (the Innovation and Knowledge Management Club) in Thailand and the co-founder of the KM Global Network. To learn more, visit www.iki-sea.org 